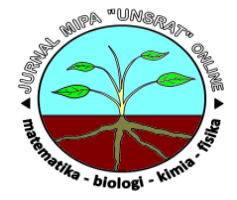

\title{
Analisis Fenolik Jerami Padi (Oryza Sativa) pada Berbagai Pelarut Sebagai Biosensitizer untuk Fotoreduksi Besi
}

\author{
Johnly Alfreds Rorong a* \\ aJurusan Kimia, FMIPA, Unsrat, Manado
}

\begin{tabular}{l} 
K A T A K U N C I \\
\hline fenolik \\
jerami padi \\
biosensitizer \\
fotoreduksi besi
\end{tabular}

\begin{abstract}
A B S T R A K
Telah dilakukan analisis fenolik dalam Jerami Padi (Oryza sativa). Penelitian ini dilakukan beberapa tahap, meliputi : persiapan sampel; ekstraksi maserasi selama 1 x 24 jam dengan berbagai pelarut: akuades, metanol, etanol dan petroleum eter; dievaporasi selama 1 jam dan dianalisis senyawa fenolik secara kualitatif menggunakan reagen Folin Ciocalteu 50\% menghasilkan ekstrak akuades (EA); ekstrak metanol (EM); ekstrak etanol (EE) dan ekstrak petroleum eter (EPE), selanjutnya dianalisis secara kuantitatif menggunakan metode spektrofotometri ultra violet visible (UV-Vis) pada panjang gelombang $750 \mathrm{~nm}$. Hasil analisis menunjukkan bahwa kandungan senyawa fenolik pada ekstrak jerami padi (JP), dengan berbagai pelarut: akuades; metanol 40; 60 dan 80\%; etanol 25; 50; 75 dan 100\%; petroleum eter, secara berturut-turut, sebesar : 1,285; 2,39; 2,72; 2,59; 1,406; 1,470; 1,501 2,996 dan 1,177 mg as. galat/L ekstrak sampel. Konsentrasi fenolik pada reaksi fotoreduksi besi dengan sinar UV dalam kotak cahaya menghasilkan ekstrak JP tertinggi terdapat pada ekstrak EM-60\%, sebesar 2,725 mg as. galat/L ekstrak sampel, sedangkan konsentrasi $\mathrm{Fe}^{+2}$ tertinggi yang terbentuk pada reaksi fotoreduksi besi ekstrak JP dengan pelarut metanol $60 \%$ sebesar $34,50 \mathrm{mg} / \mathrm{L}$ ekstrak sampel. Kandungan fenolik tertinggi terdapat pada ekstrak EE-100\%, diikuti EM-60\% dan terendah terdapat pada ekstrak EPE. Hal ini disebabkan senyawa fenolik bersifat semi polar dapat larut sempurna pada pelarut etanol bersifat polar sedangkan pelarut petroleum eter bersifat tidak polar. Reaksi fotoreduksi besi dalam kotak cahaya UV diperoleh ekstrak JP tertinggi pada EM-60\% dan konsentrasi $\mathrm{Fe}^{+2}$ tertinggi terdapat pada EM-60\%. Hal ini disebabkan ekstrak EM-60\% berpotensi sebagai biosensitizer terbaik bila dibandingkan dengan pelarut yang lain.
\end{abstract}

KEYW OR D S

phenolics

straw

biosensitizer

ferric photoreduction
A B S T R A C T

An analysis of fenolics contained in straw (Oryza sativa) has been done. The research was performed in several steps, those were sample preparation employing aquadest, methanol, ethanol, and petroleum ether, evaporation of the extracts, qualitative analysis using Folin Ciocalteu 50\%, and quantitative analysis using UV-vis spectrophotometry method at 750 $\mathrm{nm}$. The results showed that aquadest, 40, 60, and $80 \%$ methanol, 25, 50,75 , and $100 \%$ ethanol, and petroleum ether generated fenolics concentrations of 1.285, 2.39, 2.72, 2.59, 1.406, 1.470, 1.501, 2.996, and $1.177 \mathrm{mg}$ gallic acid/L, recpectively. Extract of $60 \%$ methanol gave the highest value of photoreduction and subsequently produced highest concentration of $\mathrm{Fe}^{2+}$ which was $34.50 \mathrm{mg} / \mathrm{L}$.

TERSEDIA ONLINE

10 Oktober 2015

*Corresponding author: Jurusan Kimia FMIPA UNSRAT, Jl. Kampus Unsrat, Manado, Indonesia 95115; Email address: rorongjohnly@yahoo.co.id Published by FMIPA UNSRAT (2015) 


\section{Pendahuluan}

Daerah Sulawesi Utara kaya akan sumber daya alam dengan kekayaan keanekaragaman hayati dan memiliki lingkungan tempat tumbuh kembang yang sangat menunjang bagi pertumbuhan dan perkembangan flora dan fauna tersebut. Produkproduk alami sebagai sisa atau bagian akhir dari proses kehidupan flora, seperti batang kayu,daundaunan, belum diolah dan dimanfaatkan hanya dibiarkan jatuh bertebaran dan berserakan sampai membusuk secara alami. Jerami padi yang melimpah sebagai hasilpasca panen mengandung bahan dasar atau sumber utama komponen fitokimia yaitu fenolik, flavonoid dan tanin, dapat diolah menjadi bahan biosensitizer yang bermanfaat bagi pertumbuhan tanaman, dan meningkatkan kesuburan tanah oleh bantuan cahaya matahari. Bahan biosensitizer dapat diperoleh dengan mengekstrak jerami padi menggunakan reagen tertentu dan oleh bantuan sinar ultra violet (UV) dari cahaya matahari.

Beberapa peneliti terdahulu melaporkan bahwa senyawa fenolik memiliki kemampuan untuk mereduksi suatu ion logam yang ada dalam keadaan teroksidasi. Goodman dan Cheshire (1982) telah mempelajari reduksi ion molybdenum (Mo) oleh senyawa fenolik. Dari hasil studinya diketahui bahwa sebagian ion-ion $\mathrm{MoO}_{4}{ }^{2-}$ dalam larutan akan direduksi oleh senyawa fenolik menjadi $\mathrm{Mo}^{5+}$. Baik ion $\mathrm{MoO}_{4}{ }^{2}$-maupun $\mathrm{Mo}^{5+}$, keduanya teradsorbsi oleh senyawa fenolik melalui mekanisme pertukaran ion. Selanjutnya Goodman dan Cheshire (1975) menyatakan bahwa senyawa fenolik dapat mereduksi $\mathrm{V}^{+5}$ menjadi $\mathrm{V}^{+4}$ dan $\mathrm{Hg}^{+2}$ menjadi Hgo. Pada akhirnya Goodman dan Cheshire (1982) menyimpulkan bahwa interaksi senyawa fenolik dengan agen terlarut, tidak hanya menghasilkan reduksi dari spesies dalam bentuk anion menjadi kation, tetapi juga reduksi kation menjadi kation.

Beberapa peneliti telah melakukan penelitian tentang pengaruh radiasi sinar matahari terhadap kecepatan reduksi pada senyawa mangan oksida dan besi oksida. Hasil penelitian Sunda, dkk. (1983) menunjukan bahwa reduksi mangan oksida $\left(\mathrm{MnO}_{2}\right)$ oleh senyawa fenolik yang di ekstraksi dari air laut akan dipercepat dengan adanya radiasi sinar matahari. Selanjutnya Walte dan Morel (1984) juga telah mempelajari pelarutan fotoreduktif koloid oksida besi dalam suatu air natural dengan dan tanpa adanya senyawa fenolik terlarut. Hasilnya menunjukan bahwa keberadaan senyawa fenolik terlarut dapat mempercepat reaksi pelarutan fotoreduktif oksida besi. Menurut Harborne (1987) komponen organik dapat berfungsi sebagai agen pengkhelat logam karena adanya satu gugus kaboksil dan dua gugus hidroksil yang berdekatan bereaksi dengan ion logam membentuk suatu kompleks yang stabil. Potensi tersebut ditunjukkan oleh posisi gugus hidroksilnya yang mampu menangkap radikal bebas dengan cara mengkhelat $\mathrm{Fe}$ sekaligus menstabilkan Fe. Analisis konsentrasi senyawa fenolik dilakukan untuk mengetahui potensi biosensitizer dalam suatu ekstrak, ditentukan berdasarkan kemampuan senyawa fenolik dalam ekstrak sampel yang dapat bereaksi dengan asam fosfomolibdat-fosfotungstat dalam reagen Folin-Ciocalteu yang berwarna kuning akan mengalami perubahan warna menjadi warna biru (Suryanto, 2008). Rorong (2012) telah mengekstrak senyawa fitokimia seperti fenolik, flavonoid dan tanin dalam sampel daun eceng gondok dan daun cengkih. Senyawa fitokimia dapat bertindak sebagai donor elektron bagi reaksi fotoreduksi besi di dalam tanah oleh bantuan sinar uv.

\section{Bahan dan Metode}

Sampel yang digunakan dalam penelitian ini adalah jerami padi diambil dari seputaran areal persawahan Danau Tondano Kabupaten Minahasa Provinsi Sulawesi Utara. Sampel dikeringanginkan, diblender dan diekstrak secara maserasi dengan berbagai pelarut. Bahan kimia yang digunakan sesuai kebutuhan analisis, seperti: akuades, metanol, etanol, petroleum eter, reagen Folin Ciocalteu $50 \%$, natrium karbonat, aluminium klorida.

Operasional penelitian ini dilakukan selama enam (6) bulan yaitu bulan April sampai Oktober 2015. Penelitian di laboratorium Kimia Advance dan laboraorium Kimia Organik dan Biokimia FMIPA Universitas Sam Ratulangi Manado.

Prosedur ekstraksi pelarut secara maserasi sebagai berikut; sebanyak 10 gram sampel serbuk jerami padi diekstraksi secara maserasi dengan berbagai pelarut yaitu : akuades panas; metanol: 40; 60; 80\%; etanol: 25; 50; $75 \%$ dan petroleum eter dalam erlenmeyer $100 \mathrm{~mL}$ selama $48 \mathrm{jam}$ dan disaring. Selanjutnya filtrat yang diperoleh dituangkan ke dalam wadah labu evaporator rotary dan dievaporator selama 5 jam, selanjutnya ekstrak basah yang diperoleh dituangkan ke dalam gelas arloji dan dimasukkan ke dalam oven untuk menguapkan pelarut. Selanjutnya ekstrak sampel pekat ditimbang dan dilarutkan lagi dengan akuades, dibuat pengenceran sesuai konsentarsi tertentu. Larutan disimpan pada suhu kamar sebelum dilakukan analisis.

Analisis secara kualitatif fenolik ditentukan menurut metode Folin Ciocalteu (Conde. Et., 1997). Larutan ekstrak sebanyak $0.1 \mathrm{~mL}$ di masukkan ke dalam tabung reaksi dan di tambah dengan $0,1 \mathrm{~mL}$ reagen Folin Ciocalteu 50 \%. Campuran tersebut

*Corresponding author: Jurusan Kimia FMIPA UNSRAT, Jl. Kampus Unsrat, Manado, Indonesia 95115; Email address: rorongjohnly@yahoo.co.id Published by FMIPA UNSRAT (2015) 
divorteks selama 3 menit dan di tambahkan dengan $2 \mathrm{~mL}$ larutan $\mathrm{Na}_{2} \mathrm{CO}_{3}$ 2\%. Selanjutnya campuran diinkubasi dalam ruang gelap selama 30 menit. Analisis flavonoid menggunakan metode Meda et al. (2005). Sebanyak $2 \mathrm{~mL}$ sampel ditambahkan dengan $2 \mathrm{~mL}$ aluminium klorida 2\% yang telah dilarutkan dalam etanol. Analisis tanin terkondensasi dalam sampel ditentukan menurut metode Julkunen-Titto (1985). Sebanyak 0,1 mL larutan sampel dimasukkan ke dalam tabung reaksi yang dibungkus dengan aluminium foil, ditambahkan dengan $2 \mathrm{~mL}$ larutan vanillin $4 \%(\mathrm{~b} / \mathrm{v})$ dalam metanol dan divorteks. Selanjutnya larutan ditambahkan dengan $1 \mathrm{~mL} \mathrm{HCl}$ pekat dan divorteks.

Analisis kuantitatif senyawa fenolik, flavonoid dan tanin menggunakan metode spektrofotometri UV-Vis pada panjang gelombang; 750; 415 dan 520 $\mathrm{nm}$.

Menurut Hardjono dalam Rorong (1996), analisis secara spektrofotometri UV-Vis adalah suatu metode analisis kualitatif dan kuantitatif berdasarkan pengukuran absorbansi senyawa kimia terhadap radiasi energi tertentu dengan menggunakan sinar monokromatik. Metode spektrofotometri UV-Vis didasarkan pada pengukuran intensitas sinar yang diserap oleh suatu larutan, yang sebanding dengan konsentrasi senyawa tersebut.

Persamaan hukum Lambert-Beer: $A=a b c$

Keterangan : $\mathrm{A}=$ Absorbansi; $\mathrm{T}=$ Transmitansi; $\mathrm{a}=$ Absorptivitas; $b=$ Tebal kuvet $(\mathrm{cm}) ; \mathrm{c}=$ Konsentrasi (mg/L).

\section{Hasil dan Pembahasan}

Kandungan fenolik jerami padi yang diekstrak dengan dua jenis pelarut yaitu akuades dan metanol: 40, 60 dan 80\% dapat dilihat pada Gambar 1. Hasil analisis menunjukkan bahwa fenolik pada jerami padi yang diekstrak dengan pelarut etanol $60 \%$ sebesar 2,72 $\mathrm{mg}$ as. galat/kg, ekstrak metanol $80 \%$ sebesar 22,59 mg as. galat/kg, dan ekstrak metanol 40\% sebesar 2,39 mg as. galat/kg. Kandungan fenolik terendah terdapat pada ekstrak pada akuades sebesar 2,34 $\mathrm{mg}$ as.galat/kg dan fenolik tertinggi pada ekstrak metanol 60\% kemungkinan disebabkan oleh sebagian senyawa fenolik dalam jerami padi lebih banyak larut dalam sistem tersebut.

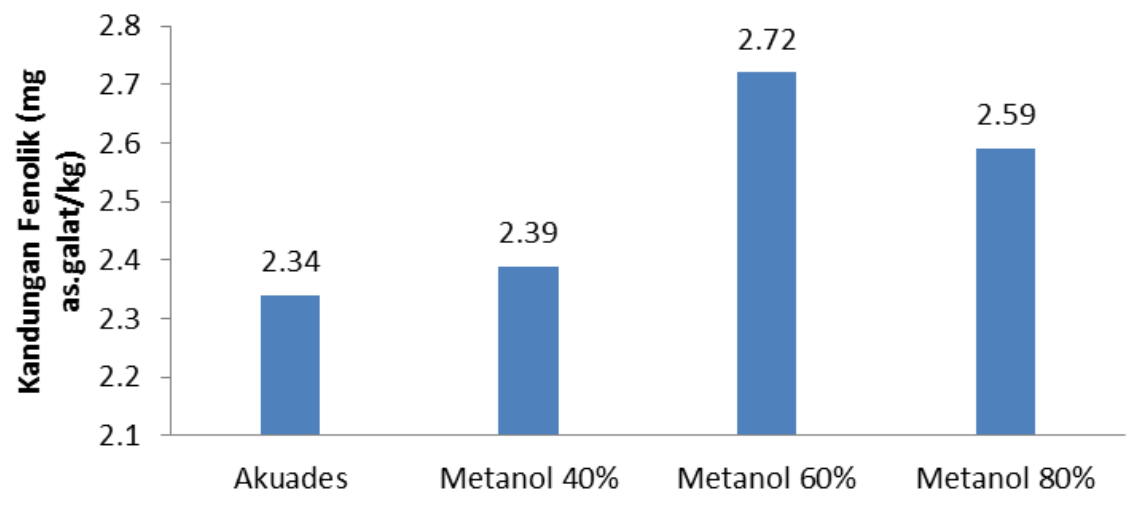

Ekstrak Jerami Padi

Gambar 1. Kandungan fenolik jerami padi yang diekstrak dengan akuades, metanol 40,60 dan 80\%.

Kandungan fenolik dalam ekstrak jerami diukur dengan larutan standar asam galat ( $\mathrm{mg} / \mathrm{kg})$. Penggunaan asam galat sebagai larutan standar disebabkan senyawa asam galat mempunyai gugus hidroksil dan ikatan rangkap yang terkonjugasi pada masing-masing cincin benzene yang menyebabkan senyawa ini sangat efektif untuk membentuk senyawa kompleks dengan reagen Folin-Ciocalteu, sehingga reaksi yang terjadi lebih sensitif dan intensif (Julkunen-Tiito, 1985).

Kandungan fenolik jerami padi yang diekstrak dengan tiga jenis pelarut yaitu akuades dan etanol: 25,50 dan 75 dan $100 \%$ dan pelarut petroleum eter dapat dilihat pada Gambar 2.

Kandungan fenolik dalam ekstrak ditentukan berdasarkan kemampuan senyawa fenolik dalam ekstrak jerami padi yang bereaksi dengan asam fosfomolibdat-fosfotungstat dalam reagen FolinCiocalteu (berwarna kuning) yang menghasilkan senyawa kompleks yaitu molibdenum-tungstat berwarna biru. Warna kuning pada reagen FolinCiocalteu akan mengalami perubahan warna menjadi warna biru karena adanya reaksi dengan ekstrak. Semakin tua intensitas warna larutan menunjukkan total senyawa fenolik dalam ekstrak semakin besar (Julkunen-Tiito, 1985). Hasil absorbansi yang diperoleh dikonversi dalam konsentrasi $(\mathrm{mg} / \mathrm{kg}$ ) dengan menggunakan larutan standar asam galat. Konsentrasi larutan standar asam galat yang digunakan adalah $30,60,90,120$ dan $150 \mathrm{mg} / \mathrm{kg}$, diperoleh persamaan garis linear y $=0,0049 x+0,0605$ dengan koefisien korelasi $\left(R^{2}\right)$ 0,9977 . 


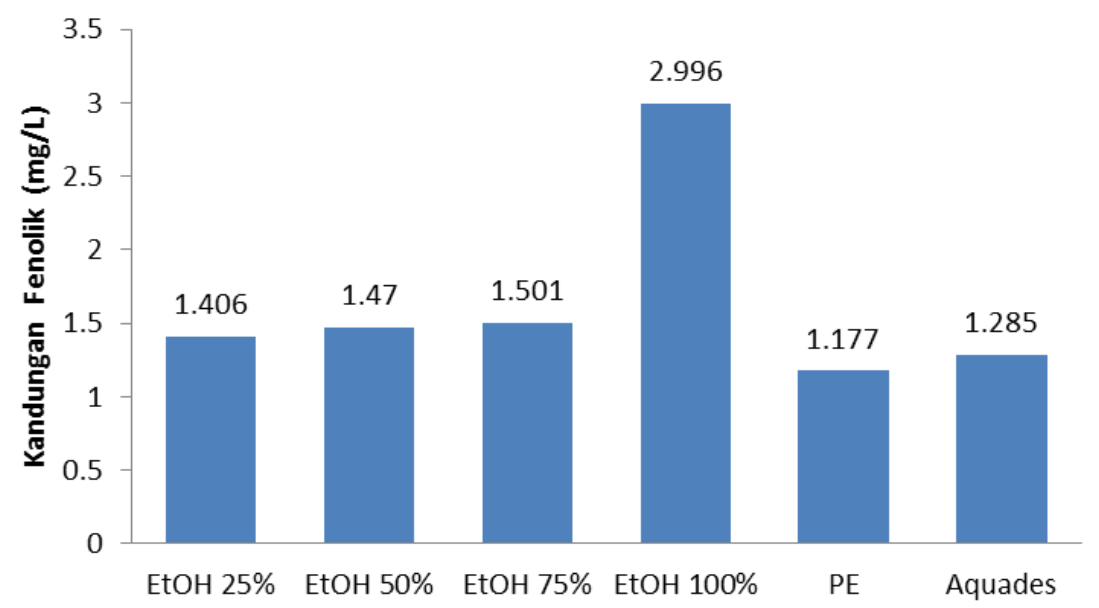

Gambar 2. Kandungan fenolik jerami padi yang diekstrak dengan akuades, etanol 25, 50 dan 75 dan $100 \%$, dan pelarut petroleum eter.

Penentuan fenolik ini bertujuan untuk mengetahui potensi senyawa fenolik dari jerami padi untuk mereduksi $\mathrm{Fe}^{3+}$ menjadi $\mathrm{Fe}^{2+}$ dalam suatu sampel. Tinggi rendahnya kandungan fenolik dalam sampel ekstrak jerami padi berhubungan langsung dengan aktivitasnya sebagai penyumbang elektron (donor elektron) dalam fotoreduksi $\mathrm{Fe}^{3+}$. Aiken et al. (1985), mengindikasikan bahwa senyawa fenolik memiliki kemampuan untuk mereduksi beberapa ion logam teroksidasi. Senyawa fenolik banyak terdapat gugus yang dapat dijadikan sebagai donor elektron, seperti gugus $\mathrm{OH}$ fenol.

Setelah ekstrak jerami padi diuji pada sistem larutan yang mengandung ion $\mathrm{Fe}^{3+}$, ekstrak tersebut diuji ke media tanah. Beberapa peneliti terdahulu melaporkan bahwa senyawa fenolik memiliki kemampuan untuk mereduksi suatu ion logam yang ada dalam keadaan teroksidasi. Goodman dan Cheshire (1982), telah mempelajari reduksi ion molibdenum (Mo) oleh senyawa fenolik. Dari hasil studinya diketahui bahwa sebagian ion-ion $\mathrm{MoO}_{4}{ }^{2-}$ dalam larutan akan direduksi oleh senyawa fenolik menjadi $\mathrm{Mo}^{5+}$. Ion $\mathrm{MoO}_{4}{ }^{2-}$ maupun $\mathrm{Mo}^{5+}$, keduanya teradsorbsi oleh senyawa fenolik melalui mekanisme pertukaran ion. Begitu juga menurut Goodman dan Cheshire (1982), senyawa fenolik dapat mereduksi V(V) menjadi V(IV) dan $\mathrm{Hg}(\mathrm{II})$ menjadi $\mathrm{Hg}(0)$. Goodman dan Cheshire (1982) menyimpulkan bahwa interaksi senyawa fenolik dengan agen terlarut, tidak hanya menghasilkan reduksi dari spesies dalam bentuk anion menjadi kation, tetapi juga reduksi kation menjadi kation.

Flores-Veles et al. (1995), telah melakukan studi spesiasi $\mathrm{Cr}(\mathrm{VI})$ dalam tanah yang mengandung senyawa fenolik menggunakan metode polarografi. Hasil studinya menunjukan bahwa pada kondisi asam ( $\mathrm{pH} 2$ dan $\mathrm{pH} 4$ ), $\mathrm{Cr}(\mathrm{VI})$ dapat direduksi menjadi $\mathrm{Cr}$ (III) oleh senyawa fenolik. Skogerboe dan Wilson (1981), yang mempelajari reduksi Hg(II) oleh senyawa fenolik, menemukan bahwa pada $\mathrm{pH}$ rendah spesies senyawa fenolik berada sebagai -
$\mathrm{OH}^{+}$. Lebih lanjut mereka menyatakan senyawa fenolik perlu diprotonasi untuk meningkatkan karakter pereduksinya. Hasil penelitian ini sejalan dengan hasil penelitian Eary dan Ray (1991) yang telah mempelajari reduksi $\mathrm{Cr}(\mathrm{VI})$ dalam tanah subpermukaan pada berbagai $\mathrm{pH}$. Hasil penelitian Eary dan Ray (1991) menunjukan bahwa reduksi $\mathrm{Cr}(\mathrm{VI})$ dalam tanah subpermukaan menjadi lebih cepat pada kondisi $\mathrm{pH}$ yang lebih asam. Menurut Flores-Velez et al. (1995), reaksi reduksi Cr(VI) oleh senyawa fenolik dapat dituliskan sebagai berikut :

3 senyawa fenolik red $\rightarrow \mathrm{SF}_{\text {oks }}+3 \mathrm{mH}^{+}+3 \mathrm{e}^{-}$

$\mathrm{HCrO}_{4}^{-}+3 \mathrm{e}^{-}+7 \mathrm{H}^{+} \rightarrow \mathrm{Cr}^{3+}+4 \mathrm{H}_{2} \mathrm{O}$

$3 \mathrm{SF}_{\text {red }}+\mathrm{HCrO}_{4}^{-}+7 \mathrm{H}^{+} \rightarrow 3 \mathrm{SF}_{\mathrm{oks}}+3 \mathrm{mH}^{+}+\mathrm{Cr}^{3+}+4 \mathrm{H}_{2} \mathrm{O}$

Flores-Veles et al. (1995) menemukan bahwa untuk menggeser kesetimbangan kearah produk maka nilai $\mathrm{m}$ harus lebih besar daripada $2 \mathrm{Cr}(\mathrm{III})$ yang terbentuk dapat terikat kesenyawa fenolik membentuk $\left(\mathrm{Cr}\left(\mathrm{SF}_{\text {oks }}\right) \mathrm{n}\right)^{3+}$.

Wittbrodt dan Palmer (1995), telah melakukan studi reduksi $\mathrm{Cr}(\mathrm{VI})$ menjadi $\mathrm{Cr}(\mathrm{III})$ dalam suasana gelap menggunakan senyawa fenolik sebagai donor elektronnya. Hasilnya menunjukan bahwa kecepatan reduksi $\mathrm{Cr}(\mathrm{VI})$ menjadi $\mathrm{Cr}(\mathrm{III})$ selain bergantung pada konsentrasi awal $\mathrm{Cr}(\mathrm{VI})$, konsentrasi awal senyawa fenolik dan $\mathrm{pH}$ larutan, juga bergantung pada perubahan jumlah fraksi senyawa fenolik yang teroksidasi selama berlangsungnya reaksi.

Hasil penelitian Sunda et al. (1983) menunjukan bahwa reduksi mangan oksida oleh senyawa fenolik yang di ekstraksi dari air laut akan dipercepat dengan adanya radiasi sinar matahari, Sunda juga telah mempelajari pelarutan fotoreduktif koloid oksida besi dalam suatu air natural dengan dan tanpa adanya senyawa fenolik terlarut. Hasilnya menunjukan bahwa keberadaan senyawa fenolik terlarut dapat mempercepat reaksi pelarutan fotoreduktif oksida besi. 
Menurut Soil Science Network (1991) pada hakekatnya, terdapat dua reaksi yang amat penting yang terjadi pada tanah, yaitu reaksi oksidasi dan reduksi. Oksidasi adalah proses kehilangan elektron dari suatu persenyawaan kimia, dari substansi atau dari atom dan radikalnya. Sedangkan reduksi adalah kebalikannya yaitu penambahan elektron pada persenyawaan di atas. Telah diketahui bahwa reaksi redoks merupakan suatu proses yang berkesinambungan dalam tanah. Dalam hal ini pemberi (donor) elektron mengalami oksidasi, sedangkan penerima (akseptor) elektron mengalami reduksi. Contoh klasik atom atau ion yang mengalami reduksi adalah sebagai berikut:

$$
\mathrm{Fe}^{3+}+1 \text { elektron } \underset{\text { oksidasi }}{\stackrel{\text { reduksi }}{\rightleftarrows}} \mathrm{Fe}^{2+}
$$

Kenaikan $\mathrm{pH}$ pada penggenangan tanah asam mungkin disebabkan bertambahnya kepekatan ion $\mathrm{OH}^{-}$akibat reduksi feri hidroksida $\left(\mathrm{Fe}(\mathrm{OH})_{3}\right)$ menurut reaksi :

$$
\mathrm{Fe}(\mathrm{OH})_{3} \rightleftarrows \mathrm{Fe}^{3+}+3 \mathrm{OH}^{-}
$$

Pada tanah asam, unsur-unsur mikro seperti besi, tembaga, seng, dan mangan terdapat dalam jumlah yang banyak dan adakalanya menimbulkan masalah keracunan bagi tanaman. Di dalam tanah, bahan organik berperan sebagai kompleks serapan tanah, kompleks ini dapat menyerap kation dan dalam jumlah kecil dapat pula menyerap anion. Ternyata terhadap ion-ion logam kegiatan liat dan humus ini tidak saja menyerap, tetapi juga membentuk senyawa kompleks atau menjepit ionion tersebut sehingga lebih sulit dipertukarkan atau dibebaskan kedalam larutan tanah. Peristiwa ini penting artinya terhadap kesuburan tanah baik dalam pembebasan hara yang terfiksasi maupun mengurangi kelarutan unsur yang meracun tanaman (Soil Science Network, 1991).

Pembentukan senyawa kompleks adalah reaksi ion logam dengan ligan (suatu senyawa organik yang dapat menjepit kation logam) melaui pasangan elektron (elektron pair sharing). Hasil reaksi ini disebut persenyawaan koordinasi logam (metal coordination compound). Dalam hal ini logam bertidak sebagai penerima pasangan elektron sedangkan ligan adalah pemberi pasangan elektron. Ion logam bertindak sebagai ion pusat, sementara ion-ion organik dikoordinasikan disekelilingnya. Beberapa ligan organik dapat mengikat ion logam dengan lebih dari satu gugusan fungsionil pemberi. Tipe pengikatan seperti ini membentuk cincin heterosiklik dan disebut khelat. Proses pembentukan cincin khelat ini disebut khelasi (chelation) (SSN, 1991). Khelasi meningkatkan mobilitas dan ketersediaan kation. Interaksi ion logam baik divalen maupun trivalen dengan gugus fungsional dalam senyawa fenolik dengan medium air pada $\mathrm{pH}$ mendekati 7 , dapat berlangsung melalui salah satu atau lebih dari mekanisme reaksi (Saragih, 2002).
Ikatan antara logam transisi dengan senyawa fenolik mulai terjadi pada situs yang menghasilkan ikatan yang kuat melalui pembentukan struktur kelat. Ikatan yang lebih lemah terjadi setelah situssitus yang kuat mengalami penjenuhan. Konsentrasi ion logam, karakter ionik pada ikatan yang terbentuk antara ion logam dengan senyawa fenolik akan meningkat.

\section{Kesimpulan dan Saran}

\subsection{Kesimpulan}

Kandungan fenolik tertinggi terdapat pada ekstrak EE-100\%, diikuti EM-60\% dan terendah terdapat pada ekstrak EPE. Hal ini disebabkan senyawa fenolik bersifat semi polar dapat larut sempurna pada pelarut etanol dan metanol bersifat polar sedangkan pelarut petroleum eter bersifat tidak polar sedangkan pelarut akuades bersifat lebih polar/sangat polar dibandingkan etanol dan metanol. Reaksi fotoreduksi besi dalam kotak cahaya UV diperoleh ekstrak JP tertinggi pada EM$60 \%$ dan konsentrasi $\mathrm{Fe}^{+2}$ tertinggi terdapat pada EM-60\%. Hal ini disebabkan ekstrak EM-6\% berpotensi sebaga biosensitizer terbaik bila dibandingkan dengan pelarut yang lain.

\subsection{Saran}

Perlu dilakukan analisis fitokimia lainnya serta reaksi fotoreduksi besi pada tanaman lainnya.

\section{Daftar Pustaka}

Aiken, G. R., D.M. Mcknight, R.L. Wershaw., dan P. MacCarthy, 1985, "Humic Substances in Soil Sediment and Water: Geochemistry, Isolation, and Characterization", John Willey \& Sons, New York. P: 23-27

Blesa, M. A., dan Matijevic, E., 1989, "Characterization of New Iron Oxides, Oxohydroxides, and Hydrous Oxides in Aqueous Media”, Elsevier Science Publisher B. V., Burda, S. Oleszek, W. 2001. Antioxidant and Antiradikal Activities of Falvonoid.J. Agric Food Chem (49):2774-2779.

Conde, E., E. Cadahia, M.C. Garcia-Vallejo, B.F.D. Simon, dan J.R.G. Adradros.1997. Low Molecular Weight Polyphenol in Cork of Qoercus Suber.J. Agric Food Chem.(45): P: 2695-2700

Cook, N.C.,SaMMAN, s., 1996., Flavonoids, Chemistry, Metabolism, Cardioprotective Effect and Dietary Sources.Nutr. Biochem, 7 :66-76.

Eary, I. E., dan Ray, D., 1991, "Chromate Reduction by Subsurface Soils Under Acidic Conditions"Soil Sci. Soc. Am. J., 55 P : 676-683

Foth,H.D., 1984, "Fundamental of Soil Science", Jhon Willey \& Sons, New York.

Goodman, B. A dan Chesshire, M V., 1982, "Reduction of Molybdate by Soil Organic Matter: EPR evidence for formation of Both $\mathrm{Mo}(\mathrm{V})$ and Mo(III)", Nature, 299 : P: 618-620.

Harbone, J.B., 1987. Metode Fitokimia, Penuntun Cara Modern Menganalisis Tumbuhan. 
Terjemahan K. Phmawinata dan I. Soediro, ITB. Bandung.

Julkunen-Tiitto, R. 1985. Phenolics Constituens in the Leaves of Northern Willows: Methods for the Analysis of Certain Phenolics. J. Agric. Food Chem. 33 P : 213-217.

Katja, D.G., E. Suryanto. 2008. Analisis Kandungan Fitokimia dan Aktifitas Penstabil Oksigen Singlet Dari Daun Kelapa. J. Chemistry Progress. FMIPA Universitas Sam Ratulangi Manado. ISSN: 19795920. Volume 1 Nomor 2: 78-84

Kojong, N., Monintja, J., Wehantow, F., Paendong, E., 2010. Phytochemical Analysis And Free Scavenging Activity From Tuis (Nicolaia speciosa, HORAN). J. Chemistry Progress. FMIPA Universitas Sam Ratulangi Manado. ISSN: 19795920 Volume 3 Nomor 1: 42-45.

Laulhere, J.P., Laboure, A.M., Briat, J.F., 1990. Photoreduction and Incporpopration If Iron Into Ferritins. Laboratoirede Biologie Moleculaire Vegetale, C.N.R.S. U.R.A. 1178, University Joseph Fourier, B.P. 53X. Biochem. J. 269, 79-84.

Meda, A.,Lamien, C. E., Romito, M., Millogo, J., Nacoulma, O. G. 2005. Determination of the Total Phenolic, Flavonoid, and Proline Contents in Burkina Fasan Money, as well as their Radical Scavenging Activity. J. Food Chem. 91P : 571577.

Mursyidi, A., 1990. Analisis Metabolit Sekunder. Universitas Gadjah Mada. Yogyakarta.

Rorong, J.A., 2007. Analisis Konsentrasi Besi (Fe) dalam Air Secara Spektrofotometri UltravioletVisible dan Sprektofotometri Atom. Jurnal IImiah Sains. Vol.7.No.1. April 2007. Penulis Tunggal. ISSN: 1412-3770; Tidak Terakreditasi. Hal. 5558.

Rorong, J.A., Suryanto, E., 2010. Analisis Fitokimia Eceng Gondok (Eichhornia crassipes) dan Efeknya Sebagai Agen Photoreduksi $\mathrm{Fe}^{+3}$. J. Chemistry Progress. FMIPA Universitas Sam Ratulangi Manado. ISSN: 1979-5920 Volume 3 Nomor 1: 33-41.

Rorong, J.A., Sudiarso., Prasetya, B., Polii-Mandang, S., 2011. Analisis Fitokimia Eceng Gondok (Eichhornia crassipes) dan Jerami Padi (Oryza sativa) Sebagai Biosensitizer Untuk Fotoreduksi Besi. Prosiding Seminar Nasional Himpunan Kimia Indonesia - FMIPA Universitas Negeri Surakarta Solo.

Rorong, J.A., Sudiarso., Prasetya, B., Polii-Mandang, S., 2011. Analisis Fitokimia Limbah Pertanian Daun Cengkih (Eugenia aromatica) Sebagai Biosensitizer Untuk Fotoreduksi Besi. Prosiding Seminar Nasional Himpunan Kimia Indonesia FMIPA Universitas Negeri Surabaya.
Rorong, J.A., 2012. Analysis of $\mathrm{Fe}^{+2}$ in Soil and Cabbage Green Leaf (Brassica junjea) Phenolic Extract With Giving As Electron Donor On The Biosensitizer -Iron Photoreduction Process. J. Tanah Tropika Universitas Lampung.

Rorong, J.A., 2012. Phytochemical Analysis of Eceng Gondok (Eichhornia crassipessolms) Of Agriculture Waste As Biosensitizer For Ferri Photoreduction Process. J. International Agrivita. Universitas Brawijaya Malang.

Rorong, J.A., 2012. Phytochemical Analysis of Water Hyacinth (Eichhornia crassipessolms) Of Agriculture Waste As Biosensitizer For Ferri Photoreduction. Agrivita Journal of Agricultural Science. Faculty of Agriculture, University of Brawijaya Malang. Penulis Utama ; ISSN ;01260537 Vol. 34. No. 30 Juni 2012; Hal 152-160. Terakreditasi: No. /DIKTI/Kep /2009. Hal. 152160.

Rorong, J.A., 2012. Ferro Content in Soil and Mustard Leave (Brassica junjea) Treated by Agricultural Waste on the Biosensitizer -Iron Production. Jurnal Tanah Tropika. Penulis Utama, ISSN 1979-7788; Vol. 17 No.3, September 2012.; Hal. 211-218. Terakreditasi: No.51/DIKTI/Kep/2010. Hal. 211-218.

Rorong, J.A., 2013. Analysis of Ferrous Ion Species In Agriculture Waste As Biosensitizer in Iron Photoreduction Process. Proceeding International: International Conference of the Indonesian Chemical Society. UII Yogyakarta, 2013 Penulis Tunggal, ISBN: 978-979-96595-45; Hal. 332-356

Saragih, B.C., 2002, "Isolasi Asam Humat dan Aplikasinya Sebagai Sensitizer Dalam Fotoreduksi Fe(III)", Program Pasca Sarjana, UGM, Yogyakarta.

Skogerboe, R. K., dan Wilson, S. A., 1981, "Reduction of Ionic Species by Fulvic Acid"J. Anal. Chem., $53 P$ : 228-232.

Stevenson, F. J., 1994, "Humus Chemistry :Genesis, Composition, Reactions", John Willey \& Sons Inc., New York.

Sunda, W. G., Huntsman, S.A., dan Harvey, G. R., 1983, "Photoreduction of Manganise Oxides in Seawater and its Geochemical and Biological Implications", Nature, 301 P : 234-236.

Suryanto, E., Rorong, J.A., 2012. Mekanisme dan Kinetika Quenching Oksigen Singlet dari Senyawa Fenolik Daun Cengkih Terhadap Fotooksidasi yang Disensitasi Oleh Eritrosin. Jurnal Teknologi Pertanian Agritech: Penulis Anggota; ISSN:0216-0455;Vol.32. No.2. Mei 2012; Hal. 117-125. Terakreditasi: No.83/DIKTI/Kep/2009. Hal. 117-125. 